\title{
A metafisica do corpo - o corpo em sofrimento no teatro de Garcia Lorca ${ }^{1}$
}

IRLEY MACHADO²

1 Artigo apresentado nas Journées scientifiques internationals: Le corps en movement. Les mouvements du corps. Émotions et passions dans la création artistique et littéraire. Organizado pela Université de Nantes França, de 10 a 12 abril de 2014. Apoio Fapemig.

2 Irley Machado, professora doutora que atua na graduação em teatro (UFU) e nos mestrados em Artes (IARTES-UFU) e Estudos Literários (ILEEL-UFU). Associada ao Laboratório CRINI (Centre de Recherche sur les Identités Nationales et l'Interculturalité), Nantes, Faculté des Langues et Cultures Etrangères. coordenadora do grupo Drapo: A dramaturgia poética de Fedrico García Lorca (IARTES) e vice-coordenadora do grupo Poeima: Poéticas do Imaginário (ILEEL). irley_machado@yahoo.com.br 


\section{- RESUMO}

Este estudo tem por objetivo analisar questões ligadas a uma temática da metafísica do corpo. Dividido em três partes, ele tenta esclarecer de inicio os postulados de uma teologia católica que aprisiona os sentidos e releva os valores do racionalismo dominante o que produz uma espécie de desconexão de toda experiência sensorial. Em um segundo momento, vamos nos deter sobre a metafísica do corpo na busca de uma resposta e da interiorização dos sentidos a partir de uma visão e de estudos realizados por homens de teatro, como Artaud, Tadeusz Kantor, Jacques Lecoq e Peter Brook - para quem o corpo assume uma importância capital e para quem é preciso atingir o espírito, abandonando o princípio racional. A partir de nossa própria experiência acrescentaremos observações sobre a rigidez e a limitação que encontramos no corpo de atores com os quais trabalhamos. Após estas considerações entraremos na análise do corpo em sofrimento na obra de García Lorca. Na dramaturgia de Lorca, os seres são reais na representação de suas dores e no aprisionamento de seus corpos negados e condicionados por uma cultura cujo autoritarismo tem por função subjugar os seres. O espaço psicofísico do texto, condensado em sua própria função, acaba por gerar um mecanismo complicado na transposição literária deste corpo texto-personagem para o corpo-intenção do ator.

\section{- PALAVRAS-CHAVE}

Metafísica, corpo, ator, dramaturgia, Garcia Lorca.

\section{- RESUMÉ}

Cette étude a pour objectif d'analyser les questions qui nous font considérer la thématique liée à la métaphysique du corps. Partagée en trois parties, elle essaye d'éclaircir d'emblée les postulats d'une théologie catholique qui apprivoisent les sens et relèvent l'importance des valeurs du rationalisme dominant et qui ont produit une sorte de déconnexion de notre propre expérience sensorielle. Dans un second temps on s'attardera sur la métaphysique du corps, à la recherche d'une réponse et de l'intériorisation des sens à partir d'une vision et d'études réalisées pour des hommes de théâtre tels que Artaud, Tadeusz Kantor, Jacques Lecoq et Peter Brook, - pour qui le corps assume une importance capitale et pour qui il faut atteindre l'esprit et le manifester, tout en abandonnant le principe rationnel. A partir de notre propre expérience on ajoutera un rapport sur la rigidité et la limitation que l'on voit dans le corps des acteurs. Après ces considérations on rentrera dans l'analyse du corps en souffrance dans l'œuvre de García Lorca. Dans la dramaturgie de Lorca, les êtres sont réels dans la représentation de leurs douleurs et dans l'apprivoisement de leurs corps niés et conditionnés par une culture dont l'autoritarisme a pour fonction de subjuguer les êtres. L' espace psychophysique du texte, condensé dans sa propre fiction, finit par générer un mécanisme compliqué dans la transposition littéraire de ce corps-texte-personnage pour le corps-intention de l'acteur.

\section{MOTS-CLES}

Métaphysique, corps, acteur, dramaturgie, García Lorca.

As questões que nos levam a considerar e a refletir sobre a temática ligada a metafísica do corpo são numerosas. Sabemos que os valores dominantes de uma cultura condicionam e podem nos desconectar de nossa própria experiência. A tradição religiosa e filosófica, subjacente à história do corpo desenvolvida por Santo Agostinho, Platão e Descartes irá atribuir um valor mínimo à existência do corpo. Se pensarmos na profunda transformação ocorrida no corpo do ser humano, com o desenvolvimento da era industrial e do desenvolvimento do pensamento cartesiano, poderemos compreender a urgente necessidade de retomarmos uma valorização diferenciada do corpo e do movimento. É preciso considerar o corpo em toda sua 
significação afetiva e erógena que nossa cultura se esforça em ignorar.

No final do século XIX o racionalismo cartesiano vai estar definitivamente instalado em inúmeros domínios da filosofia, da medicina e da educação ocidental. $O$ racionalismo, do qual Descartes é seu representante emblemático define o homem pela razão e defende esta como a única forma de conhecimento. Por outro lado a teologia católica e a manutenção em um sistema de crenças que nos coloca à mercê do julgamento de especialistas, produzem um potente impacto sobre a visão que temos de nosso próprio corpo.

A divisão teológica entre as sensações do corpo e do espírito acaba por criar uma atmosfera na qual o conhecimento sensorial é associado ao pecado e a ilusão. A religiosidade pretende possuir uma receita para o físico e outra para a alma, uma receita que nega um para salvar a outra. Nós nos encontramos diante de uma teologia que defende a busca da felicidade por meio do crescimento do sofrimento e que quer impedir a manifestação de nossos impulsos vitais e nossos pensamentos de ordem sexual. Esquece-se o que há de positivo na pulsão de vida. É então que o grande fosso cartesiano se cria. Aprende-se que a experiência sensorial subjetiva não tem nenhum valor quando comparada ao conhecimento científico.

É assim que o corpo começa a ser treinado e condicionado para servir a revolução industrial. A linha de montagem exige corpos que possam tornar-se propriedades de seus empregadores. O corpo torna-se um estranho e o eu não o reconhece mais, como se ele fosse um não eu. Para o conhecimento médico o corpo será visto como uma coleção de partes distintas e jamais como um todo. Fragmentado, seus recursos naturais e sensoriais serão empobrecidos e negados. A renúncia a sua existência como fonte significante de conhecimento irá gerar os inumeráveis males da sociedade moderna. Vivemos em uma sociedade que cria uma dicotomia entre o espírito e o corpo e dá ênfase aos preceitos de um racionalismo religioso que quer impedir o prazer. Ela se fixa na dor como única possibilidade ao homem de salvar sua alma. Seguidamente esquece-se que o corpo é o envelope e o instrumento da alma. À alma são atribuídos a justiça e o amor espiritual, e ao corpo a luxuria, a hostilidade e o peso. Em nossa cultura ocidental a vida do corpo é constantemente esboçada por imagens da morte: mesmo quando ela quer nos fazer crer na ressurreição de Jesus e na alma imortal -, são imagens de um corpo martirizado e crucificado que encontramos espalhadas pelo mundo. Como afirma a este propósito Guy Corneau: "durante longo tempo as religiões judeu-cristãs atribuíram um aspecto redentor ao sofrimento, a ponto de escolher como emblema um corpo crucificado" (CORNEAU, 2000, p. 173) ${ }^{3}$.

Don Johnson nos lembra que "aprisionados por uma ideologia, os valores dominantes de nossa cultura se insinuam em nossas respostas neuromusculares e formam nossa percepção do mundo" (JOHNSON, 1990, p. 23). São percepções que funcionam como fraturas e tornam-se um entrave em nossa capacidade de nos movermos livremente. Aprende-se a disciplinar o corpo, a organizar suas ações e a canalizar suas forças de forma utilitária, reduzindo e negando sua capacidade sensitiva e seu potencial de comunicação. Se virmos no corpo uma simples coleção de partículas organizadas no espaço, agindo sob as leis da física, e se o consideramos apenas como uma máquina, acabamos por impor sérias limitações a nossa vida sensorial.

\footnotetext{
3 No original : Pendant longtemps, les religions judéo-chrétiennes ont accordé un aspect rédempteur à la souffrance, au point de choisir comme emblem un corps crucifié. NT.
} 
No trabalho realizado com atores e alunos do curso de teatro, por meio de laboratórios nos quais a memória afetiva havia necessidade de ser ativada, as lembranças registradas nos mostraram um estado do corpo bem diferente do conhecimento que se acreditava possuir dele. É no trabalho com a arte do teatro que encontramos uma dimensão metafísica do corpo, pela vivencia de uma prática que se encontra além das leis da física.

Para Schopenhauer a metafísica funda-se sobre a impotência da física em fornecer uma explicação para tudo que se encontra por trás das interrogações sobre a natureza do homem e do mundo e sobre a finalidade da existência humana e a essência da vida. Questões que deram nascimento a ciência, a filosofia, a religião e igualmente à arte. Por outro lado encontramos uma definição da metafísica como sendo "um conhecimento pela razão e não por uma revelação de tipo religioso, de realidades imateriais, além das realidades físicas materiais" (CLEMENT, 2001, p. 287) ${ }^{4}$.

Para Nietzsche (1982, p. 476), "a arte é a atividade metafísica por excelência", mas atribuir a arte uma função puramente metafísica seria restringi-la. A maior função da arte é tornar visível ao homem à essência de um mundo inacessível ao intelecto. Antonin Artaud e Tadeusz Kantor defendem uma visão da arte que a reconcilia com a dimensão espiritual da vida. A originalidade de Artaud se afirma graças à importância capital que ele dá ao corpo nesta nova "metafísica". Na verdade sabe-se que é por meio do corpo que se consegue criar uma metafísica teatral, se assim se pode dizer, capaz de atingir o espectador. Artaud declara: "é pela pele que faremos entrar a metafísica nos espíritos" (2004, p. 565) ${ }^{5}$. Embora o autor tenha deixado às bases teóricas de seu pensamento, ele não as realizou em sua prática.

A ideia de uma metafísica ligada ao corpo por D. Lamberterie "não tem sentido a não ser à luz de um profundo questionamento de nossa civilização” (2012, p. 27) ${ }^{6}$, questões que foram colocadas pela arte do Butô. Sem querermos nos debruçar especialmente sobre esta arte, é preciso mencionar que o Butô, movimento de dança japonesa em busca de uma nova forma de expressão, aparece nos anos sessenta e se opõe as tradições artísticas do oriente e do ocidente que a precederam. Trata-se de uma dança que reenvia a um estado de espírito muito mais que a decodificações precisas e que reivindica sua filiação a Artaud. É neste sentido que se insere a definição dada por Odette Aslan sobre o Butô. Para Aslan "o Butô é uma exploração artaudiana do corpo japonês" (2002, p. 294)7, enquanto que para Myrian Sas "O Butô ... que cava selvagemente o espaço primal do pensamento, do grito e da carne, materializa de forma única, bem além do surrealismo, a herança da metafísica teatral como Artaud a havia sonhado" (2002, p. 49) ${ }^{8}$. Naturalmente existem grandes diferenças entre a proposição artaudiana e a dança Butô: o contexto cultural e histórico entre a França dos anos 1930 e o Japão dos anos 1960 é absolutamente significativo, tanto quanto os gêneros a que pertencem: teatro e dança. Existem, entretanto, pontos comuns entre essas artes: $O$ dançarino como o ator deve se transformar para tornar-se criança, velho, homem, mulher, animal, etc.

\footnotetext{
${ }_{4}$ No original : La connaissance, par La raison ET non par une révélation Du type religieux, dês réalités immatérielles, au-delà des réalités physiques matérielles. NT.

5 No original : C'est par La peau qu'on fera rentrer La métaphysique dans lês esprits. NT.

6 No original : N'a de sens qu'à La lumière d'une profonde remise em question de notre civilisation. NT.

7 No original : Le butô est une exploration artaudienne du corps japonais. NT.

8 No original : Le butô... que fouille sauvagement l'espace primal de La pensée et le cri de la chair, matérialise de façon unique, bien au-delà Du surréalisme, l'héritage de La métaphysique théâtrale telle qu'Artaud l'avait rêvee. NT.
} 
A metafísica do corpo defendida por Artaud por meio de uma arte teatral inovadora e fora dos parâmetros conhecidos, tanto quanto a dança Butô, coloca em cheque as bases de nossa cultura e de certa forma constitui-se numa espécie de revolta contra ela. Somos constantemente agredidos por mensagens não verbais que modelam nosso corpo e somos educados para não confiarmos em nosso conhecimento sensorial. Wilhelm Reich, em seus estudos sobre o corpo, concluiu que as ideologias autoritárias tiram proveito do controle sobre as pulsões corporais do homem e exigem um ser de corpo endurecido e resistente ao prazer. Entretanto, não se pode esquecer que é em função da dor ou do prazer que nosso corpo se torna consciente.

\section{Uma experiência}

O teatro e seus jogos são sempre o resultado de uma experiência vivida e não apenas o resultado de uma prática fundada sobre exercícios técnicos. Neste sentido a questão que se coloca é como tornar possível esta experiência aos neófitos da arte teatral. Qual a bagagem que eles trazem sendo tão jovens? Como auxiliá-los a transcender o movimento mecânico do corpo no espaço? Como dar um sentido ao movimento para criar uma manifestação metafísica do corpo dos atores? Tornar-se um encenador ou professor desta difícil arte, torna-se uma busca de respostas a ideia seguinte: como tornar o corpo consciente de suas emoções, consciente da vida física e sensorial e o tornar presente em sua totalidade e não somente como um presença física sobre a cena. É preciso ensinar pra conhecer e aprender. É ensinando que descobrimos e que compreendemos melhor os mecanismos desta metafísica, quando o ator deve lançar-se inteiro em busca de uma expressão carregada de significação. É ensinando, por meio da observação das realidades humanas que se descobre que o corpo sabe e conhece coisas que nosso pensamento ignora. É exatamente este gênero de coisa que é preciso manifestar, para construir o jogo do ator no qual encontramos o mistério, o fantástico, o grotesco. É pela observação que o ator se apropria do jeito como os seres e as coisas tomam forma sobre a cena, como eles se refletem em nós e como nós os refletimos. Se por um lado é fundamental estar atento a tudo que existe de forma intangível fora de si mesmo, é somente a partir de uma referência conhecida que os atores encontram sua própria forma de expressão.

Nosso teatro ocidental não permite que os atores tenham o tempo suficiente para desenvolver, uma experiência que favoreça a introjeção de imagens geradoras de movimentos a partir de uma relação com seu eu intimo e profundo. Por outro lado, nossa cena não aceita os movimentos estilizados do teatro oriental. Então, onde buscar o elo que potencialize um trabalho no corpo para que este possa alcançar uma dimensão metafísica.

Quando se trabalha o teatro é o movimento do personagem - de um rei, de uma rainha, ou de um criado - em sua essência a mais sensível, na urgência de viver que se deve procurar levar a cena. Não se trata de transformar a realidade cotidiana, mas de abraçá-la, de saudá-la, de lhe dar uma nova vida, sempre a partir de si - mesmo. É ela que se transforma quando nos apropriamos do personagem ao invés de reproduzi-lo simplesmente. Para Kantor "são os acontecimentos e os fatos, pequenos ou importantes, sejam eles neutros e cotidianos, convencionais, tediosos, que criam o impacto da realidade" (2008, p. 140).

No momento de empreender o trabalho prático da encenação do espetáculo 
Yerma de Federico García Lorca, encontramo-nos diante de um quadro preocupante: os participantes apesar de sua formação teatral e de seu domínio do aspecto físico do jogo e do corpo, demonstraram uma consciência corporal deficitária. Havia alguns que não conheciam seus mecanismos de respiração, o que bloqueava a pélvis e impedia a interiorização das sensações necessárias à criação do personagem. Entre os exercícios adotados como auxiliar no desenvolvimento do processo de sensibilização e na criação de uma memória corporal, seguimos alguns conceitos e exercícios utilizados por Lowen e ligados à bioenergética:

\begin{abstract}
A bioenergética, como outras terapias, pretende ajudar a pessoa a desenvolver um melhor senso do eu, isto é, a ser mais ela própria. O eu, entretanto, não é uma qualidade abstrata, mas a totalidade do funcionamento desta pessoa. $\mathrm{O}$ eu não pode ser separado da autoexpressão, porque é nas atividades expressivas que nós o percebemos. Todavia, ao contrário do que muita gente pensa, não é necessária a via consciente para tentar expressar este eu. A maior e mais importante parte de nossa autoexpressão é inconsciente [...] Se uma pessoa está bloqueada na sua habilidade de expressar sensações e sentimentos, estará amortecendo seu corpo e reduzindo sua vitalidade (LOWEN, 1985, p. 57).
\end{abstract}

O trabalho de laboratório tinha a intenção de auxiliar os atores a desenvolverem seu autoconhecimento e a se conectarem ao seu eu corporal adormecido. Para os atores, habituados a um trabalho de técnicas corporais mecânicas, mergulhar neste eu negligenciado, mas rico de sensações inexploradas, gerava certo receio e ao mesmo tempo se constituía num desafio. Fazê-los sentir e tornar presente, compreender a importância de realizar um movimento com a consciência plena da ação - fosse ela física ou emocional - que estava acontecendo foi uma tarefa difícil. Como afirma Jacques Lecoq "o movimento não é um percurso, é uma dinâmica, outra coisa além de um simples deslocamento de um ponto a outro. O que importa é como se faz o deslocamento. O fundo dinâmico [...] é constituído pelas relações entre ritmos, espaços e forças" (LECOQ, 1997, p. 32) ${ }^{9}$ e acrescentaríamos emoções e sensações justas.

O desenvolvimento de uma técnica nem sempre promove a sensação correta e necessária a expressão, na qual a origem do movimento parte de uma reação física criada por uma emoção interior. Segundo Kantor, "o ambiente que acompanha a criação de uma obra de arte está sistemática e consequentemente mimado pelo movimento, pelo automatismo, pelo acaso, pelo informe, pelo equívoco do sonho, pela destruição e, pela colagem" (2008, p. 140). É justamente o automatismo do ator que é necessário rever e repensar. Aprender técnicas de dança, não é necessariamente dançar: se minha alma não dança comigo e com meu corpo, a dança não acontece. É fundamental sentir, se deixar guiar pelo corpo onde encontramos níveis sutis de movimentos que negligenciamos. É necessário manter a emoção viva, atingir o espírito e manifestá-lo por meio do corpo, esquecendo o princípio racional. Assim, no trabalho com os atores era preciso fazê-los treinar este corpo físico sem priorizálo enquanto forma. Exercitar o corpo criando novas memórias para utilizá-lo como

\footnotetext{
No original : Le mouvement n'est pas un parcours, c'est une dynamique, autre chose qu'un simple déplacement d'un point à un autre. Ce qui importe c'est comment se fait le déplacement. Le fond dynamique [...] est constitué par les rapports de rythmes, d'espaces, des forces. NT.
} 
algo novo: buscar onde no indivíduo - ator pulsa a dor do personagem. Observar e recriar. Atualizar a pulsação vibratória dolorosa do ator para encontrar a metafísica do próprio corpo, para fazê-lo entrar em frequência com o fluxo corporal do personagem. Construir o imaginário no espaço para provocar um encontro entre o corpo do ator - o corpo do personagem e o espectador. Construir por meio do movimento do corpo liberado de seus entraves e de toda censura uma realidade diferente, mais profunda, mais viva, mais comunicativa.

A consciência da emoção pode provocar a transformação do que é mecânico em algo de vivo capaz de evoluir. Para Kantor a evolução do artista não é um "aperfeiçoamento da forma" (p. 100), mas uma aventura e uma surpresa constante e permanente. Assim a relação entre a realidade do "eu" ator que representa o "eu" personagem, não é uma relação imutável nem fixa, ela vem carregada de vida.

Há uma realidade espiritual invisível que faz parte de nossa identidade corporal real e profunda. Para realizar um trabalho de arte e, sobretudo, com a arte do teatro é necessário estar em possessão de nossa identidade plena, o que significa estar consciente da realidade metafísica de nosso corpo. É esta consciência que coloca o ator em disponibilidade para a devoção que o teatro exige. Se as leis do movimento organizam as situações teatrais pode-se dizer que um texto é uma estrutura organizada em movimento. Um texto é bem mais que um objeto: ele é um material histórico, um documento: o registro de uma ou mais vidas pessoais e, por vezes um arquivo cultural.

O texto literário nos é apresentado como algo de definitivo, algo condensado que possui seu próprio espaço psicofísico e se encontra submisso às mesmas leis orgânicas que tudo o que participa de um espetáculo teatral: os acontecimentos e os corpos que se mimam sobre a cena. Como lembra Peter Brook "o teatro não é apenas um lugar, não é apenas uma profissão. Ele é uma metáfora. Ele ajuda a tornar mais claro o processo de vida" $\left(1997\right.$, p. 309) ${ }^{10}$. Se o teatro em sua origem possuía a capacidade de purgar emoções, devia-se ao seu poder de cura: quando a população reunida em um espaço definido e sob condições particulares participava de um mistério, uma cura momentânea reconciliava os membros dispersos com a comunidade e verdades profundamente ocultas a propósito da condição humana eram expressas.

\section{O corpo em sofrimento}

Una cosa es querer con la cabeza y otra es que el cuerpo, !maldito sea el cuerpo!, no nos responda.

Callar y quemarse es el castigo más grande que nos podemos echar encima.

No puedo oír tu voz.

Es como si me bebiera una botella de anís y me durmiera en una colcha de rosas... Mirando sus ojos me parece que bebo su sangre lentamente...

\footnotetext{
${ }^{10}$ No original : Le théâtre n'est pas un lieu, n'est pas seulement une profession. II est une métaphore. II aide à rendre plus claire les processus de la vie. NT
} 
Federico García Lorca em toda sua obra teatral e lírica permanece um observador fascinado por certos enigmas presentes na relação entre o homem e o cosmos no qual o jogo teatral nasce. O autor, carregado de uma forte consciência social, poeta, diretor e homem de teatro, nos mostra sua vontade de ir em direção a um público popular com um teatro simples e direto. Ele cria um teatro pleno de uma poesia sensível capaz de denunciar o sofrimento de seres que não são nem mais nem menos do que o duplo da realidade, uma realidade invisível, perigosa, quando olhada de frente e que somos muitas vezes levados a negar. Para estudar Lorca é preciso ver além dos limites do texto. O poeta afirmou que sua obra e seus personagens são seres saídos da observação e o fruto da realidade. Ele declarou: rigurosamente autentico es el tema de cada una de sus figuras. O homem de teatro que era Lorca perguntava a outros dramaturgos: A que no eres capaz de expresar la angustia del mar en un personaje? (1957, p. 32) e acrescentava em uma de suas conferências :

El teatro es la poesía que se levanta del libro y se hace humana. Y al hacerse, habla y grita, llora y se desespera. El teatro necesita que los personajes que aparezcan en la escena lleven un traje depoesía y al mismo tiempo seles vean los huesos, la sangre. Han de ser tan humanos, tan horrorosamente trágicos y ligados a la vida y al día con una fuerza tal, que muestren sus traiciones, que se aprecien sus olores y que salga a los labios toda la valentía de sus palabras llenas de amor o de ascos (GARCIA

É bem a ideia subterrânea de seus personagens que Lorca defende. Seu realismo é, pois, profundo e nos parece que se projeta em direção ao simbolismo, em que uma tragédia intima e cotidiana aparece e onde cada personagem esconde um símbolo. Jung dizia que "aquilo que nosso pequeno ego acredita ser não é a totalidade, é uma aquisição cultural” (1969, p. 211). Atrás dele há o inconsciente, este mundo subterrâneo que conhecemos tão pouco: há todo um universo mais potente e milhares de anos da história da humanidade. Assim, quando pensamos na história de uma Espanha amordaçada, reduzida ao silêncio por séculos de autoritarismo, é no sofrimento experimentado pelo corpo feminino, obrigado a calar-se que pensamos. Deste sofrimento encontramos bem uma amostra na dramaturgia de Lorca. No dramaturgo os seres são passionais e o sofrimento que vivem não é senão o resultado dos desejos em que a vida se manifesta e a paixão torna-se fatalidade. $A$ injustiça do mundo e a dor de corpos impedidos de expressarem seus sentimentos tornam-se sofrimento.

Pode-se começar por analisar um personagem chave de seu teatro: Yerma. Segundo a etimologia da palavra ela é uma mulher estéril, seca como a terra desértica, o que nos remete a desnaturalização do desejo sexual do corpo feminino. É um corpo desejante, mas infértil. Entretanto sua esterilidade nos parece muito mais psicológica, reforçada pela indiferença do marido, pelo sentido de integridade da heroína, pela manutenção da honra e pela constante vigilância a que se vê submetida por parte de suas cunhadas. Ela carrega um desejo obsedante e quer atingir uma felicidade que lhe escapa: a felicidade de tornar-se mãe.

$\mathrm{O}$ corpo da personagem é um corpo em sofrimento. Em seu desejo ela quer experimentar " un gran dolor... un dolor fresco, bueno, necesario para la salud (como a dor de sua irmã)... que daba de mamar a su niño con el pecho lleno de grietas" (1957, p. 
1193). Esta dor ela a suportaria, mas ela não suporta mais ser possuída por um marido "que quando me cubre hace su deber, pero yo le noto la cintura fria, como si tuviera el cuerpo muerto" (1957, p. 1239). Seu desejo pela criança que não chega torna-se um veneno corrosivo que a queima, faz sofrer seu corpo e destrói sua alma. Yerma é a personagem que põe em cheque a questão que colocamos no inicio de nossa exposição: o racionalismo exacerbadamente desenvolvido impede o corpo de sentir, de realizar-se em toda sua potência. Há um momento no texto que ela exclama: Una cosa es querer con la cabeza y otra es que el cuerpo, ! maldito sea el cuerpo!, no nos responda (1957, p. 1245). A jovem não compreende: é com o corpo que ela deve querer e não com a cabeça. Ela se comporta de forma diferente da Velha pagã que exclama, tentando fazê-la compreender: Yo me he puesto boca arriba y he comenzado a cantar. Los hijos llegan como el água (1957, p. 1198). Esta Velha deitada de costas sobre a terra, em uma posição de espera, representa um corpo que experimenta a sensação de uma mulher planta, uma mulher terra, o símbolo de uma fertilidade que Yerma não alcançará jamais: seu corpo em sofrimento não responde aos seus anseios. Em uma passagem ela diz a Maria: Yo no debo tener manos de madre (p. 1227). As palavras da personagem são significativas. A mão tem uma importância fundamental na evolução da espécie humana, ela possui uma dimensão criativa e afetiva. Sem as mãos não se pode tocar e as relações de afeto são amputadas. A mutilação de uma mão significa a perda de contato concreto com seu ambiente. Marie-Louise Von Franz afirmava que "são sempre as heroínas que se fazem cortar as mãos e nunca os heróis porque é a criatividade feminina que foi reprimida pela cultura patriarcal" (VON FRANZ, 1979, p. $147)^{11}$. Mutilada a personagem perde contato com a criação que deve vir de suas entranhas e não pode mais controlar seu destino. As exigências de seu ser primordial, de seu sangue feminino, de sua carne, não serão jamais satisfeitas: ela será condenada a sofrer para sempre o vazio de seu corpo, um vazio metafísico. Yerma morrerá sem ter experimentado o prazer da maternidade que tanto desejava: não podendo tornar-se mãe ela se deixará absorver pela mãe terra.

Lorca faz transcender a identidade cultural de suas heroínas sutilmente. Suas personagens irão expressar seu sofrimento corporal por meio de um discurso da alma feminina adormecida.

Em Bodas de Sangue encontramos a mesma dor dos personagens que não conseguem realizar suas pulsões vitais o que provoca um profundo sofrimento. Tomemos como exemplo a personagem da Noiva e Leonardo. São seres tocados pelo fogo da paixão. Segundo Bachelar, o fogo é sempre o objeto de uma interdição social. Um fogo que não apenas aquece, mas que é capaz de destruir tudo que toca. Leonardo é um personagem cheio de fogo, alguma coisa queima em seu interior. Em seu dialogo com a Noiva ele declara: No quiero hablar, porque soy hombre de sangre (1957, p. 1123). Um sangue que ferve, domina e se espalha como a larva de um vulcão e cujo desenrolar se anuncia trágico. Leonardo é um digno representante do enxofre, igneo, corrosivo. Sua personalidade está ligada ao desejo sexual, ao poder e a satisfação imediata. Em seu carácter corrosivo ele é como uma chama na qual se encontram intimamente ligados o instinto de vida e morte. Seu desejo durante um longo tempo reprimido explode como um vulcão que vomita enxofre, metal e fogo.

\footnotetext{
${ }^{11}$ No original : Ce sont toujours les héroïnes qui se font couper les mains et jamais les héros parce que c'est la créativité au féminin qui a été réprimée par la culture patriarcale ». NT.
} 
Quando ele se aproxima da Noiva, diz : “Callar y quemarse es el castigo más grande que nos podemos echar encima. » (1957, p. 1124). Leonardo acabará por consumir-se em sua própria chama, fundir-se em seu próprio elemento ígneo.

Em todo o texto é bem a imagem de um fogo que queima o corpo e dilacera a alma, devido a esta impossibilidade de concretizar o amor que os une, que se manifesta. A Noiva olhando Leonardo se sente impotente para aliviar o desejo que a queima, entregando-se a ele, ou libertando-se definitivamente deste desejo. Ela experimenta igualmente o ardor deste sentimento que a dilacera, e que não pode ser descrito, um sentimento, um fogo impossível de arrancar e que o tempo não apaga. No texto há um verdadeiro desfile de sentidos que denunciam o desejo insaciado. A Noiva diz : "No puedo oír tu voz. Es como si me bebiera una botella de anís y me durmiera en una colcha de rosas... » (1957, p. 1125). São sensações físicas nas quais todos os sentidos estão presentes : ouvir, ver, tocar, ser tocada; é a voz que ela escuta, é a sensação de estar embriagada, de afogar-se, de alongar-se sobre um leito de rosas e por meio do contato das pétalas aliviar o calor de um corpo em chamas. É a irresistível atração que grita e a sensação de um sangue aprisionado no corpo e a ferver no interior do peito. É o sofrimento de um corpo que não sabe e que não encontra uma forma de tornar-se livre. Após a morte dos personagens masculinos, quando a Noiva encontra a personagem da Mãe ela se justifica:

Yo era una mujer quemada, llena de llagas por dentro y por fuera... y el otro me mandaba cientos de pájaros que me impedían el andar y que dejaban escarcha sobre mis heridas de pobre mujer marchita, de muchacha acariciada por el fuego... (1957, p. 1179).

Assim ela esclarece seu ato e sua incapacidade em controlar seu desejo. 0 fogo não representa apenas a imagem da destruição, aqui ele representa a força do amor. Um amor que acaricia e faz explodir tudo que toca. Este amor é o elemento que pela fricção provoca o calor e cuja faísca incendeia : é um fogo íntimo, um fogo primordial, luz incandescente que nos inflama. Como diz Bachelar: "O amor não é senão um fogo a transmitir. O fogo não é senão um amor a surpreender" (1999, p. 59). Em Bodas de Sangue o amor entre os personagens é bem a expressão de um fogo profundo que a proximidade física acende. Um fogo cuja origem vem carregada de afetividade e que a negação mentirosa de um desejo íntimo não pode ocultar. 0 sofrimento experimentado por um corpo submetido a opressão da sociedade e a auto repressão do desejo e do instinto erótico não pode senão tornar-se um corpo mutilado, um corpo incapaz de erradicar sua dor atroz.

Em A casa de Bernarda Alba encontramos Adela, personagem que desde o início do texto mostra sua revolta e não esconde seu instinto erótico em movimento na busca da plenitude. É uma jovem de 20 anos que não quer estar confinada. Nesta casa em que a morte parece ser a presença a mais marcante, ela se sente como um pássaro em uma gaiola. Ela quer a todo custo fugir desta casa cárcere onde não encontra espaço para realizar-se, onde sente sua juventude fenecer como uma flor e sua pele tornar-se pálida.

Adela se deixa arrebatar por um amor proibido e não oferece resistência. Condenada a viver em uma atmosfera que se torna o signo de um calor abrasador, tudo nela grita por liberdade. Obrigada a vivenciar suas emoções às escondidas, ela se sente devorar por um incêndio interior, um fogo tão vulcânico como o da Noiva de Bodas de Sangue. 
No imaginário de Lorca, Adela irá se tornar uma vítima, por ter escolhido viver e ter ousado fazer dom de seu corpo e de seu amor a um homem que lhe era proibido, por ter querido viver o doce martírio das carícias masculinas. Corajosa ela vai romper com o modelo de comportamento tradicional. Ela permite que os valores de Eros sejam lançados contra uma sociedade hipócrita em que predominam valores como honra, moral, virgindade, obediência e fidelidade no casamento, sem considerar o individuo e suas necessidades prementes e sagradas. Adela se permite viver um momento decisivo na vida de todas as mulheres: o do despertar erótico, que emergindo de seu inconsciente ira proporcionar o encontro individual com o masculino e o reconhecimento do amor. Ela assume seu sexo com ousadia e vive sua emoção com toda a intensidade. Ela se desembaraça da angustia coletiva e torna-se um individuo, embora não sem sofrimento. Em seu diálogo com La Poncia ela conta já o sofrimento que vive, pelo amor a Pepe: «Mirando sus ojos me parece que bebo su sangre lentamente ». (1957, p. 1392).

Sabe-se que o sofrimento psicológico é tão verdadeiro quanto o sofrimento físico. Em um mundo marcado pela fatalidade, em que os dramas de seus personagens tornam-se a narrativa de revoltas impossíveis, segredos ocultos queimam e ao serem revelados impulsionam os seres à morte. Lorca cujo imaginário foi profundamente alimentado pela cultura espanhola, desnuda brutalmente as forças misteriosas e íntimas da natureza dos seres e que transcendem seus segredos. São seres que sofrem, que queimam, animados pelo fogo da paixão e pela impossibilidade de compartilhar seus segredos. Segredos que devoram, signo de pertencimento a potências que fazem com que todos os sentidos participem deste embriagar da paixão que é preciso esconder a todo preço, mas que nenhuma prisão pode reter por muito tempo. Os personagens se dilaceram na tentativa de ocultar seus segredos, mas a vida neles se manifesta com tal violência que os ultrapassa e torna-se a razão de seu intolerável sofrimento.

Tendo conhecimento da problemática que envolve os seres lorquianos e desejando encenar as obras Yerma e Bodas de Sangue a grande questão que se colocava era: como fazer para que os atores transmitissem sobre a cena a dor dos personagens. Onde encontrar neles, além das técnicas e dos mecanismos de interpretação que eles conheciam a chave das emoções que poderiam ser compatíveis com o sofrimento destes seres de ficção? Como libertar os atores desta carapaça racional e fazê-los sentir com o corpo? Não se pode mentir em cena, pois, o corpo desmente e os espectadores percebem. Foi necessário um longo e doloroso percurso. Começamos por ajudá-los a descobrir as antigas sensações da infância quando o corpo não havia ainda registrado os interditos sociais. Era preciso brincar e brincar muito. Fazê-los dançar sem coreografia, fazê-los cantar desafinado, fazê-los correr até perderem o ar, tomar banho de chuva, saborear o silêncio, comer frutas sem descascá-las, tocar com o corpo, sem o uso das mãos, cheirar como animais, rolar na terra, caminhar na água com os pés nus, amassar o barro, enfim criar sensações que pudessem lhes fornecer uma nova memória corporal e aproximá-los dos personagens de Lorca, personagens dotados de uma vida toda deles.

Fazendo isto eu me obrigava a sentir com eles e quando os escutei chorar compreendi que estavam prontos para a cena. Como dizia Grotowsky é preciso de início "purificá-los" para poder sensibilizá-los. Eles não poderiam manifestar nenhum a priori sobre os personagens que deveriam interpretar. Durante as montagens vivemos experiências enriquecedoras em conjunto: havia vida em cena e não a simples representação técnica. Alguns fenômenos em nível corporal foram experienciados. A atriz que representava o 
papel da personagem Mãe em Bodas de Sangue apresentava um ricto do lado esquerdo de seu rosto, que o deformava e que ela não conseguia controlar. Ele pertencia ao personagem e não a atriz, assim era necessário incorporá-lo ao papel e deixá-lo acontecer.

Após esta experiência houve uma mudança importante na forma de interpretar dos atores. Alguns testemunharam que se sentiam mais vivos em cena e que estavam buscando diferentes formas de descobrir seus personagens. Formas que lhes permitiriam sentir com o corpo e não apenas expressar a ideia que eles possuíam do personagem a ser representado. Eles haviam atingido um nível superior no jogo cênico e haviam permitido que uma verdadeira metafísica do corpo se estabelecesse, tendo dado vida aos seres e aos corpos em sofrimento do teatro de Lorca.

\section{Referências}

ARTAUD, Antonin. Le théâtre et son double. Oeuvres. Paris: Gallimard, 2004.

ASLAN, Odette ; PICON-VALLIN, Béatrice. Butô. Paris: CNRS, Editions, 2002.

BACHELAR, Gaston. La psychanalyse du feu. Paris: Gallimard. 1999.

BROOK, Peter. Les voies de la création théâtrale. Paris: CNRS, 1985. V. XIII

CLÉMENT, Elizabeth. La pratique de la philosophie de A à Z. Evreux: Hatier, 2001.

CORNEAU, Guy. La guérison du cœur. Paris: Ed. Robert Laffont, S.A., 2000.

GARCÍA LORCA, Federico. Obras completas. Madrid: Aguilar, 1957.

JOHNSON, Don. Corpo. Tradução de: Adauri Bastos. Rio de Janeiro: Ed. Nova Fronteira, 1990.

JUNG, Carls. Los complejos y el incosciente. Madrid: Alianza Editorial, 1969.

KANTOR, Tadeusz. O teatro da morte. São Paulo: Ed. Perspectiva S.A., 2008.

LAMBERTERIE, Domitie. La métaphysique de la chair. Lille: Éditions du Cénacle de France, 2012.

LECOQ, Jacques. Le corps poètique. Arles: Actes Syd, 1997.

GARCÍA LORCA, Federico. CEuvres Complètes II. Édition établie para André Belamich. Paris. Ed. Gallimard, 1990.

LOWEN, Alexander. Exercícios de Bioenergética: o caminho para uma saúde vibrante. São Paulo: Ágora, 1985.

NIETZSCHE, Friedrich. Fragments posthumes, Paris, Gallimard, 1982.

VON FRANZ, Marie. O Processo de individuação. In: Jung, Carl. O homem e seus símbolos. Tradução de: Maria Lúcia Pinho. Rio de Janeiro: Nova Fronteira, 2002. 